\title{
Viejos remedios para nuevos males. El caso del plasma de convalecientes
}

\author{
Old remedies for new evils. \\ The case of convalescent plasma
}

Angel Guerra Márquez*

\begin{abstract}
Resumen
El uso de plasma como fuente de transferencia pasiva de anticuerpos tiene más de 100 años de experiencia. La inmunidad pasiva es una técnica para adquirir, de manera inmediata y transitoria, protección mediante la administración de anticuerpos específicos contra el agente patógeno en cuestión, a través del plasma obtenido de convalecientes o individuos inmunizados. En tiempos recientes, el empleo del plasma de convalecientes se ha asociado con la aparición de nuevos agentes patógenos como los causantes de SARS, MERS, Ébola y COVID, ya que al carecer de tratamientos efectivos o vacunas eficaces, es necesario recurrir a los viejos, pero potencialmente efectivos, procedimientos médicos.
\end{abstract}

Palabras clave: Inmunoterapia pasiva, plasma de convalecientes, inmunidad pasiva, inmunoglobulinas.

\section{Abstract}

The use of plasma as a passive antibody transfer source has more than 100 years of experience. Passive immunity is a technique to acquire immediate and transient protection by administering specific antibodies against the pathogen in question, through plasma obtained from convalescent or immunized individuals. In recent times, the use of convalescent plasma has been associated with the emergence of new pathogens such as those causing SARS, MERS, Ebola and COVID, as the lack of effective treatments or effective vaccines requires the use of old but potentially effective medical procedures.

Keywords: Pasive immunotherapy, convalescent plasma, pasive immunity, immunoglobulin.
* Banco Central de Sangre del Centro Médico Nacional «La Raza».

Citar como: Guerra MA. Viejos remedios para nuevos males. El caso del plasma de convalecientes. Rev Mex Med Transfus. 2020; 13 (1):27-30. doi: 10.35366/95497

Rev Mex Med Transfus 2020; 13 (1): 27-30

\section{El surgimiento de la inmunoterapia pasiva}

El concepto de inmunoterapia pasiva surgió a fines del siglo XIX. En 1888, Émile Roux, discípulo de Pasteur, descubrió que el mecanismo patogé- 
nico de la difteria está asociado con una toxina, lo que hoy en día conocemos como toxina diftérica. Por su parte, Émile von Behring, trabajando en Berlín, descubrió la manera de inmunizar animales de experimentación a partir de la toxina descrita por Roux. Con la ayuda de Shibasaburo Kitasato, von Behring inició una serie de experimentos en los que, inyectando toxina diftérica a cobayos no tratados previamente, obtenían una «antitoxina» que, inyectada a animales de experimentación que sufrían la enfermedad, lograban su recuperación. Aún más, la administración de la «antitoxina» protegía a los animales que recibían dosis letales de la toxina diftérica. A este tratamiento le llamaron «terapia sérica». Sus trabajos dieron pie a la llamada «Ley de Behring»: la sangre y el suero de un individuo inmunizado transferidos a otro individuo provocan la inmunización de éste. Entre 1892 y 1894 el grupo de von Behring trató con éxito a unos 20 mil niños afectados de difteria. Von Behring sería el primer receptor del Premio Nobel de Medicina en 1901. A estos dos personajes, Roux y von Behring, se les puede considerar como los precursores de la inmunidad pasiva.

Hoy en día, sabemos que ante cualquier agente infeccioso «nuevo», lo primordial es la identificación del agente causal, ya que con esto es posible desarrollar métodos diagnósticos que permiten identificar a aquellos individuos que, siendo portadores de la infección, pueden no manifestar síntomas de ésta, y confirmar en los sintomáticos la causa de su enfermedad. El siguiente paso es desarrollar métodos terapéuticos, ya sea a base de medicamentos con acción específica sobre el agente infeccioso, y vacunas que brinden protección mediante inmunidad adquirida.

Estos dos elementos terapéuticos, medicamentos y vacunas, requieren tiempo para su desarrollo y puesta a punto para uso masivo. Pero cuando se trata de un agente contagioso y con cierto grado de letalidad, es necesario recurrir a tratamientos más inmediatos. En este escenario es que entra la inmunidad pasiva suministrada por el plasma de convalecientes. ${ }^{2}$

Llama la atención que un mismo agente infeccioso puede provocar manifestaciones diversas en personas diferentes: tendremos aquéllos que se infectan y no manifiestan ningún dato de la infección, hasta los que desarrollan manifestaciones graves que los llevan incluso a la muerte. ¿Qué factores influyen en estos desenlaces tan diversos? Sin duda, la inmunidad juega un papel importante, al igual que el estado nutricional del individuo, las comorbilidades que manifieste, así como la edad, entre otros. Pero en todo escenario en que se encuentre involucrado un agente infeccioso «nuevo», se contará siempre con aquéllos que sufrieron la enfermedad y han logrado superarla al desarrollar inmunidad humoral contra el patógeno en cuestión. Estos individuos pueden ser fuente de obtención de anticuerpos humanos. La inmunidad pasiva es una técnica para adquirir de manera inmediata y transitoria protección mediante la administración de anticuerpos específicos contra el agente patógeno en cuestión a través del plasma obtenido de convalecientes. ${ }^{3}$

Este fenómeno de inmunidad pasiva a partir de donantes convalecientes ha sido empleado, observado y analizado desde tiempos añejos, como por ejemplo durante la epidemia de la fiebre española en 1918, ${ }^{2}$ sarampión en 1934 en los Estados Unidos, y en tiempos más recientes como la epidemia de SARS-CoV, MERS en 2012, Ébola en $2015,{ }^{4}$ y SARS-COV-2 en 2020.5

Si bien es cierto que el plasma de convalecientes se ha empleado históricamente desde hace más de 100 años, otros productos sanguíneos han sido utilizados en el tratamiento de enfermedades infecciosas, tal es el caso de las inmunoglobulinas. Este derivado sanguíneo es obtenido a través de mezcla de plasma o suero de donantes sanos, o de donantes que han sido vacunados o convalecientes de determinado agente infeccioso, siendo 
entonces productos hiperinmunes. ${ }^{6}$ Pero al igual que las vacunas y los fármacos de acción específica, su elaboración requiere tiempo, por lo que la terapia más inmediata sigue siendo el plasma de convalecientes.

\section{Eficacia y seguridad del plasma de convalecientes}

Aunque son controversiales por razones diversas como limitado número de pacientes, estudios no aleatorizados, no cegados, entre otras causas, existen múltiples reportes de los efectos benéficos de esta modalidad terapéutica. En general, los resultados coinciden en una disminución de la mortalidad, 7,8 reducción en los días de estancia hospitalaria, ${ }^{9,10}$ reducción en el uso de terapia ventilatoria invasiva y disminución de la carga viral, ${ }^{17} \mathrm{y}$ mejoría del estado general. ${ }^{12}$ En cuanto al perfil de seguridad, los efectos adversos reportados son los comúnmente asociados con este componente: reacción alérgica es el más frecuente, seguido por la sobrecarga circulatoria asociada con transfusión (TACO por sus siglas en inglés), aunque la mayoría de los autores no reportan efectos adversos a la administración del plasma. ${ }^{3}$

\section{¿Cuál es el mecanismo de acción del plasma de convalecientes?}

Se ha propuesto que la transferencia pasiva de anticuerpos reduce la carga viral en el paciente, permite que la respuesta inmunológica de tipo adaptativo sea más robusta, con disminución de la tormenta de citocinas y del fenómeno de hiperinflamación y autoinmunidad. ${ }^{14-16}$

Desde el punto de vista de los bancos de sangre, es posible establecer el perfil del donante idóneo: paciente recuperado de infección por SARS-CoV-2, diagnosticado mediante hisopado nasofaríngeo con técnica de biología molecular (RT-PCR), captado idealmente a los 28 días del inicio de los síntomas, que cuente con una segun- da prueba molecular negativa al momento de la donación, obtener el componente mediante procedimiento de aféresis, y en términos generales debiendo cumplir con los criterios de la legislación nacional. ${ }^{17}$

En resumen, aún con lo controversial del procedimiento, mantiene un lugar importante en la terapéutica de agentes infecciosos nuevos, ya que no hay otra alternativa que posibilite la atención específica fuera de las medidas generales de sostén. La inmunoterapia pasiva llegó para quedarse.

\section{Referencias}

1. Biographical: Emil von Behring. [Consultado julio 2020] Available in:www.nobelprize.org/prizes/medicine/1901/behring/biographical

2. Brown BL, McCullough J. Treatment of emerging viruses: convalescent plasma and Covid-19. Transfus Apher Sci. 2020; 59: 102790.

3. Marano G, Vaglio S, Pupella S, Facco G, Catalano L, Liumbruno GM et al. Convalescent plasma: new evidence for an old therapeutic tool? Blood Transfus. 2016; 14: 152-157.

4. Fischer JC, Zänker K, Griensven M, Schneider M, Kindgen-Milles $\mathrm{D}$, Trudo KW et al. The role of passive immunization in the era of SARS-Cov2: an update. Eur J Med Res. 2020; 25: 16.

5. Psaltopoulou T, Sergentanis TM, Pappa V, Politou M, Terpos E, Tsiodras $\mathrm{S}$ et al. The emerging role of convalescent plasma in the treatment of COVID-19. Hemasphere. 2020; 4 (3): e409.

6. Bozzo J, Jorquera Jl. Use of human immunoglobulins as an anti-infective treatment: the experience so far and their possible re-emerging role. Expert Rev Anti Infect Ther. 2017; 15 (6): 585604.

7. Ye M, Fu D, Ren Y, Wang D, Shang F, Xia X et al. Treatment with convalescent plasma for COVID-19 patients in Wuhan, China. J Med Virol. 2020; 10/jmv.25882.

8. Hung IF, To KK, Lee CK, Chan K, Yan WW, Liu RR et al. Convalescent plasma treatment reduced mortality in patients with severe pandemic influenza A (H1N1) 2009 virus infection. Clin Infect Dis. 2011; 52 (4): 447-456.

9. Alzoughool F, Alanagreh L. Coronavirus drugs: Using plasma from recovered patients as a treatment for COVID-19. Int J Risk Saf Med. 2020; 31 (2): 47-51.

10. Duan K, Liu B, Li C, Zhang H, Yu T, Qu J et al. Effectiveness of convalescent plasma therapy in severe COVID-19 patients. Proc Natl Acad Sci U S A. 2020; 117 (17): 9490-9496.

11. Shen C, Wang Z, Zhao F, Yang Y, Li J, Yuan J et al. Treatment of 5 critically ill patients with COVID-19 with convalescent plasma. JAMA. 2020; 323 (16): 1582-1589.

12. Zeng QL, Yu ZJ, Gou JJ, Li GM, Ma SH, Zhang GF et al. Effect of convalescent plasma on viral shedding and survival in patients with Coronavirus disease 2019. J Infect Dis. 2020; 222 (1): 38-43.

13. Salazar E, Perez KK, Ashraf M, Chen J, Castillo B, Christensen PA et al. Treatment of Coronavirus Disease 2019 (COVID-19) patients with convalescent plasma. Am J Pathol. 2020; 190 (8): $1680-1690$ 
14. Rojas M, Rodríguez Y, Monsalve DM, Acosta-Ampudia Y, Camacho B, Gallo JE et al. Convalescent plasma in Covid-19: possible mechanisms of action. Autoimmun Rev. 2020; 19 (7): 102554.

15. Henderson LA, Canna SW, Schulert GS, Volpi S, Lee PY, Kernan $\mathrm{KF}$ et al. On the alert for cytokine storm: immunopathology in COVID-19. Arthritis Rheumatol. 2020; 72 (7): 1059-1063.

16. Ye Q, Wang B, Mao J. The pathogenesis and treatment of the 'Cytokine Storm' in COVID-19. J Infect. 2020; 80 (6): 607-613.
17. Li L, Tong X, Chen H, He R, Lv Q, Yang R et al. Characteristics and serological patterns of COVID-19 convalescent plasma donors: optimal donors and timing of donation. Transfusion. 2020; 10.1111/ trf.15918.

Correspondencia:

Dr. Angel Guerra Márquez

E-mail: angel.guerra@me.com 